\title{
NAQŠBANDĪ E MALĀMATĪ: UNA QUESTIONE DI METODO
}

\author{
Demetrio Giordani (Università di Modena e Reggio Emilia)
}

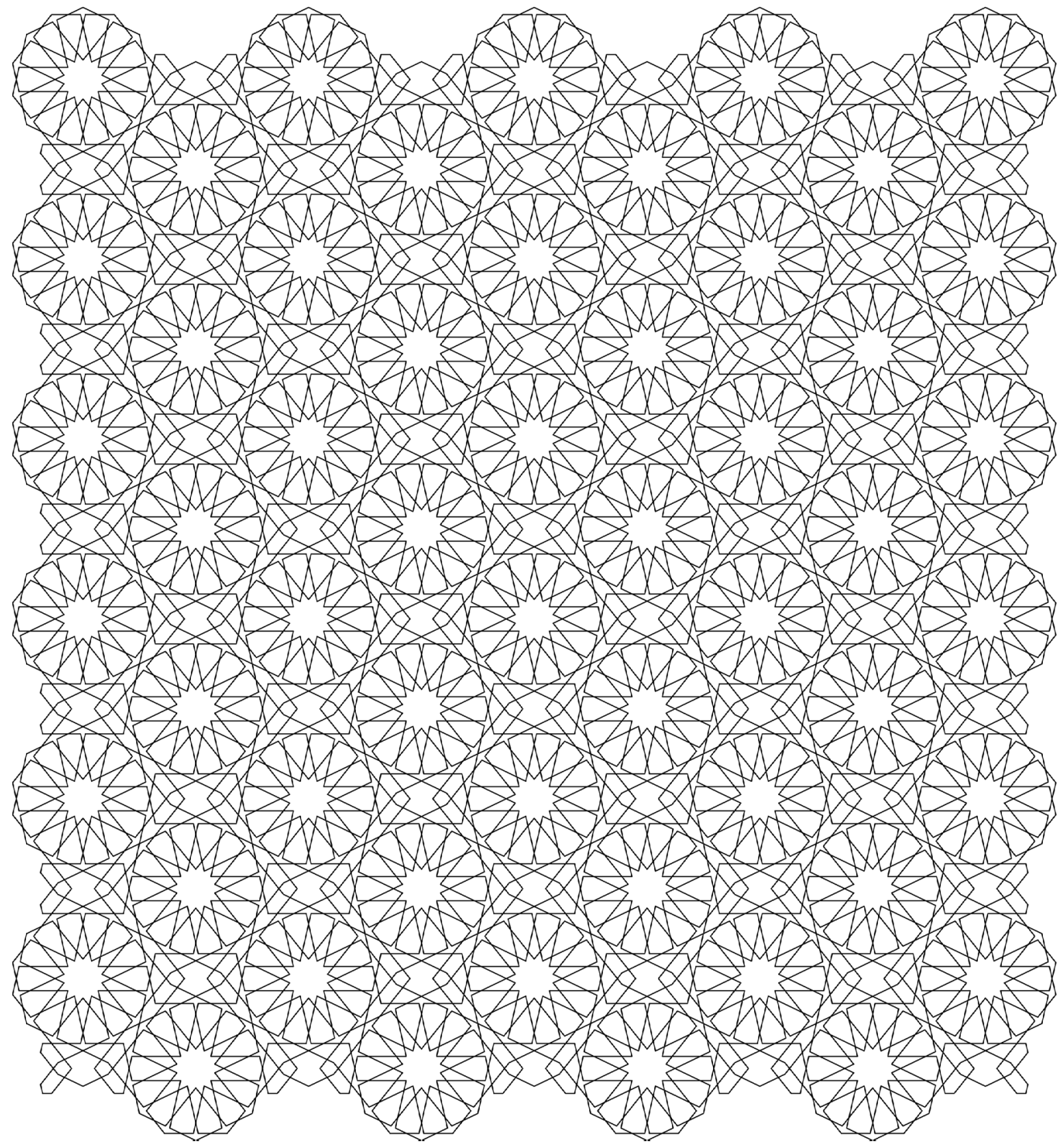


Riassunto: Tra le correnti più antiche della storia del Sufismo, i Malāmatiyya sono in particolare coloro che seguono "La Via del Biasimo" e che nel loro comportamento agiscono in modo da non lasciare nessuna traccia della propria attitudine spirituale tra la gente che li circonda. Secondo Abū 'Abd al-Raḥmān Al-Sulamī essi erano un gruppo di asceti che vivevano nella città di Nišāaūr alla fine del IX secolo: molti autori dicono che uno dei più importanti appartenenti a questa scuola fosse stato Bayazīd al-Bisțāmī (m. 874). Nel XIII secolo i Ḩwājaḡān, una corrente diffusa ampiamente nell'Asia centrale durante l'epoca del dominio dei mongoli Chagatay, praticavano una ritualità molto simile a quella dei Malāmatiyya di Nišāpūr, basata sulla "menzione del Nome di Dio in segreto" (dikr-i hafî) e sulla "solitudine tra la folla" (halwat dar anjoman). Due di questi Huwājagàān furono i maestri di Huwāja Bahā’uddīn Naqšband (m. 1389). I temi e la pratica della "Via del Biasimo" riappaiono nella tradizione naqšbandī e acquistano profondità e solidità dottrinale nell'opera di Šayḩ Aḥmad Sirhindī (m. 1625) il "Rinnovatore del secondo millennio" dell'Islām (muğaddid-i alf-i tāañ $)$.

Parole chiave: Islām, Sufismo, Malāmatiyya, Naqšbandiyya, Sirhindī. $\therefore$

Abstract: Among the oldest currents in the history of Sufism, the Malāmatiyya are especially those who follow "The Path of Blame" and who in their behaviour act in such a way as to leave no trace of their spiritual attitude among the people around them. According to Abū 'Abd al-Rahmmān Al-Sulamī, they were a group of ascetics who lived in the town of Nišāpūr at the end of the 9th century: many authors say that one of the most important members of this school was Bayazìd al-Bistāimì (m. 874). In the 13th century the Huaàjagàan, a current widespread in Central Asia during the era of the rule of the Chagatay Mongols, practiced a rituality very similar to that of the Malāmatiyya of Nišsāpūr, based on the "mention of the Name of God in secret" (dikr-i hafi) and on "solitude in the crowd" (halwat dar anjoman). Two of these Huwājagāan were the masters of Hwwāja Bahā'uddīn Naqšband (d. 1389). The themes and the practice of the "Way of Blame" reappear in the naqšbandī tradition and acquire doctrinal depth and solidity in the work of Šayh Ahmad Sirhindì (d. 1625), the "Renewer of the Second Millennium" of Islam (muğaddid-i alf-i $i \underline{t a n} \vec{\imath}$ ).

Keywords: Islām, Sufism, Malāmatiyya, Naqšbandiyya, Sirhindī. 
Nelle sue Malfūzāt Huwāja 'Ubaydullāh Ahrār (m.1489), uno dei più importanti maestri naqšband̄̄ di Samarcanda, dichiara a chiare lettere che: «I precursori della tarīqa dei Huājaḡān sono i Malāmatiyya e i Malāmatiyya sono il gruppo che fanno in modo che il loro aspetto esteriore nasconda il loro legame d'Amore». ${ }^{1}$

Se nel primo periodo della sua storia, la Naqšbandiyya è denominata țariqa baqriyya o tayfüriyya, nel secondo periodo essa è contraddistinta dai cosiddetti "Antichi Maestri", i Huwājaḡān, una corrente diffusa ampiamente nell'Asia centrale durante l'epoca del dominio dei mongoli Chagatay (dal XIII, fino a metà del XIV secolo) e che comprendeva vari gruppi impegnati in diversi tipi di pratiche rituali; alcuni di questi sopravvissero nella regione fino al XVI secolo. Nella storia, o meglio nella silsila della Naqšbandiyya i Ḩwājağān, sono sette šuyūh centroasiatici, il primo dei quali fu Ḩwāja Abū Ya'qūb Yūsuf Hamadān̄̄ (m.1141) e l'ultimo Huwāja Amīr Sayyid Kulāl (m. 1371) il maestro di Ḩwāja Bahā’uddīn Naqšband.

In questa tradizione è fondamentale la figura di 'Abd al-Ḩāliq Ġuğdūwān̄̄ (m. 1179 o 1220), originario di Ġuğdūwān nei pressi di Buhāra; a lui, infatti, viene attribuita l'introduzione di una forma di $\underline{d i k r}$ silenzioso e l'istituzione di otto degli undici principi che costituiranno in seguito le pratiche fondamentali dell'ordine.

\section{“LA SOLITUDINE IN MEZZO ALLA FOLLA" (HALWAT DAR ANJOMAN)}

Un giorno re Husayn di Herat domandò a Huwāja Bahā'uddīn Naqšband su cosa fosse edificata la sua via, disse: «Nella vostra tarīqa, vi sono $\underline{d i k r}$ a voce alta, concerto spirituale $(s a m \bar{a}$ ) e clausura contemplativa (halwat)?» Il Hwāja rispose: «No». Il re chiese allora: «In che consiste dunque la vostra tarīqa?» Il Hwāja rispose: «Nelle parole della gente di 'Abd alḨāliq Guğdūwān̄̄, che le loro anime siano santificate: la solitudine tra la folla». Il re allora domandò che significassero quelle parole, Huwāja Bahā’uddīn rispose: «Essere esteriormente con le creature e interiormente con il Vero». ${ }^{2}$

Il principio naqšband̄̄ della "solitudine nella folla" (halwat dar anjuman), forse il principio più indicativo tra gli undici, ha un indubbio sapore malāmatī. L'attitudine a nascondere agli occhi della gente la propria realtà interiore e a fare del tutto per apparire esteriormente insignificanti, è tipica di quel gruppo di șûfî che Huğwīrī, per primo, chiama Malāmatiyya o "gente del

biasimo" e che Šarîf al-Ğurğānī (m.1413) definisce come: «Chi non manifesta nel loro essere esteriore ciò che contiene il loro essere interiore e che si sforza di realizzare perfettamente la

1 Mīr 'Abd al-Awwāl Nīšābūrī: "Malfūzāt-i Ahrār", in: Aḥwāl va Suhanān-i Ḩwāja 'Ubaydullāh Ahrār, a cura di 'Ārif Nawšāhī, Teheran 1380 h. š., p.524.

2 Salāḥ ibn Mubārak Buhārī: Anīs al-țāibīn wa 'uddat al-șălihiñn. Kanpūr 1901, Istanbul 2010, p.44. 
sincerità (ihhlās) nel culto». ${ }^{3}$ Muhyyìddīn Ibn 'Arabī parla dei Malāmatī, nelle Futūhăt, come di quelli che "conoscono, ma non sono conosciuti", il cui rango spirituale è superiore a quello

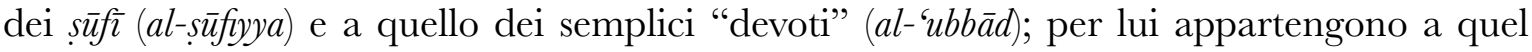
gruppoil Profeta stesso, Salmān al-Fārisī, Abū Sa ‘̄ìd al-Ȟarrāz e Bayazīd al-Bisțāmī. ${ }^{4}$

Al-Sulamī (m.1021), l'autore di una delle prime raccolte di biografie e di detti dei primi șûtì, identifica i primi Malāmatiyya nel gruppo che originariamente si riuniva a Nī̌sāpūr intorno alle figure di Abū Hafṣ al-Haddād (m.874), ${ }^{5}$ Abū 'Uțmān al-Hīrī (m.910) ${ }^{6}$ e Hamdūn alQașạār (m.884), ${ }^{7}$ che secondo lui è stato il vero fondatore del movimento ${ }^{8}$ e che forse è il rappresentante della sua tendenza più autentica. Tra i suoi detti più famosi: «La conoscenza che Iddio ha di te è migliore di quella che hanno gli uomini». ${ }^{9}$ Al-Sulamī aveva una conoscenza diretta di quell'ambiente per le informazioni che gli aveva trasmesso suo nonno, Isma íl ibn Nuğayd (m.977), anche lui uno di quelli che metteva in pratica il principio della "dissimulazione dell'esperienza interiore" (talbis al-hâal); con il suo aiuto fu in grado di scrivere numerose opere sull'argomento, tra cui un breve e intenso trattato chiamato per l'appunto "L'Epistola della Gente del Biasimo" (Risālat al-Malāmatiyya).

Vi è stata poi, nella letteratura del Sufismo posteriore all'XI secolo, un'attenzione particolare nel definire la condizione spirituale della categoria dei Malāmatí, a cominciare da 'Alī ibn 'Uțmān al-Hujwīrī (m.1072), che nel capitolo del suo libro dedicato alla Malāma scrisse:

«In particolare, questa gente (ìn țầifah) si distingue su tutte le creature dell'universo per aver scelto di essere biasimata per il bene della loro anima (dil); questo alto grado non è stato raggiunto da nessuna creatura, né dai ravvicinati (muqarrabān), né dagli Angeli più Approssimati (karrubiyān), né da nessun altro essere spirituale (rūhāāiyān), né è stato raggiunto da asceti, devoti, nobili appartenenti alle nazioni dell'antichità;

3 Šarīf al-Ǧurğān̄i: Kitāb al-Ta'rñfât, Beirut, Librairie du Liban, 1983, pag.248.

4 Michel Chodkiewicz: "Les Malâmiyya dans la doctrine de Ibn 'Arabî” in Melâmis-Bayrâmis. Études sur trois mouvements mystiques musulmans. Réunies par Nathalie Glayer, Alexandre Popovic et Thierry Zarcone. Les Éditions ISIS Istanbul 1998, pp. 15-25. William C. Chittick: The Sufi Path of Knowledge. Ibn al-Arabi's Methaphysics of Immagination, SUNY 1989, pp.372-375.

5 Al-Sulamī Abū 'Abd al-Rahmān: Al-Ṭabaqāt al-Ṣūfyya, Al-Qāhira 1997, pp. 38-39.

6 Ivi, pp. 39-41

7 Ivi, pp.53-55.

8 Ivi, pp. 123-129. Dichiara l'autore che «Da lui si diffuse la scuola dei Malāmatî (wa-minhu intašara madhab al-malâma)» ivi, p. 123; Abū Nu'aym Al-Işfahānī: Hilyat al-Awliyā’ wa-tabaqāt al-Asfiy $\bar{a}$, Beirut, sd, X, 231; Abū-l-Qāsim Al-Qušayrī: Al-Risāla al-Qušayriyya, Beirut 2001, p. 19.

9 Hujwîrî 'Alī ibn 'Utmān: The Kashf al-Mahjub the Oldest Persian Treatise on Sufism, a cura di R.A. Nicholson, Lahore 1976, p.183. 
esso è riservato a un certo gruppo di questa nazione che percorre la strada (tañ $q$ ) dell'astensione del cuore (dalle cose di questo mondo)». ${ }^{10}$

È soprattutto Muhyīddīn Ibn 'Arabī a definire il rango, gli attributi e la funzione dei Malāmat̄̄. Nel lungo capitolo LXXIII delle sue Futūhāt, consacrato alle trentacinque Tabaqāt al-Awliyā', le "Categorie dei Santi", al-Šayh al-Akbar descrive la gerarchia occulta dei santi musulmani, che opera segretamente in base al mandato divino, dalla sommità, dal grado dei "Poli" (aqtāb), scendendo gradualmente ai due Imām, ai quattro Awtād, ai sette $A b d \bar{a} l$, ecc. fino ai trecento Ādamiyyūn, la categoria più numerosa. ${ }^{11}$ All'inizio della seconda parte di questo capitolo, al-Šayh al-Akbar parla dei Malāmiyya come del grado più alto nella gerarchia dei santi musulmani. Essi sono, secondo lui:

«I nobili tra gli uomini della gente della Via di Allāh e le loro guide (a'immatuhum). Il principe dell'Universo, Muhammad, l'Inviato di Dio, fa parte del loro gruppo. Essi sono i saggi che mettono le cose al posto che compete loro. [...] Quel che spetta a questo mondo essi lo lasciano a questo mondo, e lasciano all'Altro quel che spetta all'Altro. Essi osservano le cose con lo sguardo con cui le osserva Iddio...I Malāmiyya (sono coloro) dei quali è celato il valore, che conosce solo il loro Signore». ${ }^{12}$

Resta il fatto che bisogna considerare la "Via del Biasimo" come un'attitudine spirituale e non come una vera e propria scuola organizzata; in altre parole, se ne può parlare come di un mašrab e non di una tarī $q a,{ }^{13}$ e come tale affiora con modalità diverse, in luoghi e tempi anche molto differenti fra loro.

La catena di trasmissione iniziatica (silsila) dei maestri della Naqśbandiyya, non contiene nomi che possano essere messi in relazione direttamente con i Malāmat̄̄ di Nī̌sāpūr, però contiene i nomi di Bāyazīd Bisțāmī e Salmān al-Fārisī che vengono da più parti indicati per il loro temperamento spirituale come dei Malāmatī; in più l'anello di collegamento della silsila dei Naqśband̄̄ con il Profeta dell'Islām, è Abū Bakr (e non 'Alī b. Abī Ṭālib com’è nella maggior parte dei casi); così è anche per la silsila del gruppo malāmatí di Nīšāpūr. Da questo fatto, in particolare, deriverebbe anche una delle caratteristiche in comune tra la tañ̄qa naqšsbandiyya e i primi Malāmatī, che è l'invocazione silenziosa del Nome di Allâh (dikr-i

10 Ivi, p. 67.

11 A proposito della gerarchia iniziatica e dei suoi gradi, vedere Ibn 'Arabī: Il mistero dei custodi del mondo (Kitâb manzil al-qutb wa-maqâmu-hu wa-hâlu-hu) a cura di C. Casseler, Torino 2001.

12 Muhyīiddīn Ibn 'Arabī: Al-Futūhāt al-Makkiyya, Il Cairo 1329 h. (4 vol.) vol. II, p.16. Vedere anche M. Chodkiewicz: "Les Malâmiyya dans la doctrine d'Ibn 'Arabî" in Melamis-Bayramis, cit., p. 17.

13 Hamid Algar : "Eléments de provenance malâmâtî dans la tradition primitive naqshbandî " in: Melamis-Bayramis, cit., p. 27. 
hafi) che secondo la tradizione, il Profeta avrebbe insegnato ad Abū Bakr nella caverna del monte Tawr, la notte della migrazione (hiğra) da Mecca a Medina. Altra somiglianza tra i Naqşband $\bar{\imath}$ e i primi Malāmatī, è il loro comune atteggiamento nei confronti del samă'e delle altre manifestazioni di ritualità esteriore legate all'audizione di musica sacra; a tal riguardo Ḩwāja Bahāuuddīn Naqšband disse, con un gioco di parole: «Noi non lo pratichiamo e non lo condanniamo» (mā na īn kār mīkonìm, na inkār mì̄konìm). ${ }^{14}$ Lo Šayh al-Sulamī ci riporta un detto di un Malāmati a cui era stato chiesto perché non partecipava alle audizioni rituali (samā̄), e quello aveva dato la seguente risposta: «Non ci asteniamo dalle audizioni rituali perché non ci piacciono o perché le disapproviamo, ma perché temiamo che in esse appaiano gli stati che noi teniamo celati». ${ }^{15}$

Oltre alle rassomiglianze sul piano dei principi spirituali, possiamo parlare di un orientamento sociale comune ai Malāmati e ai primi Naqšbandī: entrambi, infatti, erano legati all'ambiente degli artigiani e dei commercianti del bazār. Si è sempre affermato che il movimento dei Malāmatī si diffuse all'interno delle corporazioni di mestiere (asnāf) di Nišāpūr e all'organizzazione socio-etica della Futuwrwa, e possiamo analogamente immaginare che ciò sia accaduto anche per i Naqšsbandī di Buhārāā, a giudicare dal gran numero di artigiani e commercianti presenti nel gruppo dei discepoli di Ḩwāja Bahā’uddīn Naqšband. ${ }^{16}$

Essendo piuttosto una virtù o un temperamento spirituale che riaffiora periodicamente in alcune vie del tasawreuf, la sua diffusione è veramente difficile da documentare. Abū Yazīd (Bayazìd) al-Biștāmī (m.874 o 848) non era in alcun modo ricollegato con il gruppo di Nī̌sapūr, nonostante questo il suo temperamento spirituale è indubbiamente quello di un malāmatī. Alcuni dei suoi detti lo rivelano chiaramente: "Chiesero ad Abū Yazīd: "Qual è il segno più importante dello gnostico?" Egli rispose: "È che tu lo vedi che mangia con te, beve con te, scherza con te, ti vende qualcosa, ti compra qualcosa, mentre il suo cuore è nel Santo Dominio. Questo è il segno più importante"».. ${ }^{17}$

14 'Alī al-Safí: Rashahât 'ayn al-hayât. Beads of Dew from the Source of Life, a cura di Mukhtar Holland, Lauderdale 2001, p. 73.

15 Al-Sulamī Abū 'Abd al-Raḥmān: Risāla al-malāmatiyya, trad. it.: I custodi del segreto, a cura di G. Sassi, Milano 1997, pp. 38-39.

16 Hamid Algar suppone un legame ideale e una notevole affinità tra i primi Malāmatī di Nī̌āāūr e i Naqšsbandī della Transoxiana. Entrambi i gruppi facevano del tutto per non distinguersi dai semplici credenti: evitavano di portare indumenti distintivi, non abitavano in una hănqāh o in un altro edificio particolare, esercitavano un mestiere, appartenevano all'élite urbana e avevano legami con la $f u-$ tuwrwa. "Eléments de provenance malâmâtî dans la tradition primitive naqshbandî" in Melâmis-Bayrâmis, cit, pp. 28-29.

17 Abū 'Abd al-Raḥmān al-Sulamī: Risāla al-Malāmatiyya, in Abū al-'Alā al-'Afifí: Al-Malāmatiyya wa al-Süfyya wa ahl al- Futurwera, Beirut-Baghdad 2015, p. 97. 
Farīduddīn 'Aț̣ār (m.1221) uno dei più famosi poeti sụfī persiani, racconta che quando Bayazīd si stava recando in Pellegrinaggio alla Mecca, passò per un villaggio, in cui tutti gli abitanti, compresi i più nobili, avevano deciso di unirsi a lui, a causa della fama di grande santità che lo aveva preceduto. Quando uscì dalla città, tutta la popolazione lo seguì. Bayazìd, quando li vide, chiese chi fossero: «Sono persone che desiderano la tua compagnia», gli risposero $\mathrm{i}$ suoi compagni. «O mio Dio! - egli esclamò - non vorrei che, per colpa dell'attaccamento di questa gente, Ti allontani da me scomparendo dietro un velo». Per strappare poi dai cuori di quella gente l'affetto che portavano per lui, e volendo togliersi dall'imbarazzo, lasciandoli andare per la loro strada, dopo aver guidato la salāt dell'alba, si girò e disse, fissandoli negli occhi: «In verità, Io sono Allāh, non c'è altra divinità al di fuori di Me, adorami e compi la preghiera! ». ${ }^{18}$ Quelli, udendo queste parole, dissero con voce unanime: «Ma quest'uomo è un pazzo!». Si allontanarono tutti e lo abbandonarono, ma lui non aveva fatto altro che recitare per loro la Parola di Dio. ${ }^{19}$

Da segnalare, infine, che l'atteggiamento che ha imposto il nome ai Malāmatiyya, in altre parole la disapprovazione implacabile di sé, il rifiuto di accontentarsi dei propri stati e del compiacersi dell'opinione altrui, in molte occasioni è stato fatto proprio dai Naqšbandī. Un Malāmatī si considera peggiore di tutte le creature e il più indegno; il suo sforzo principale è quello di tenere costantemente sotto osservazione la propria anima per individuarne i difetti e umiliarla. Il suo obiettivo finale è il raggiungimento della massima sincerità (ihlāas) nel culto, restando solo con Dio, lontano dagli occhi della gente ed evitare il pericolo dell'ipocrisia (riy $\left.\bar{a}^{\prime}\right)$ nascosta nell'ostentazione della propria pratica devota e dei propri traguardi spirituali. ${ }^{20}$

Si racconta che Ḩwāja 'Alā’uddīn 'Aț̣ār, riportando le parole di Ḩwāja Bahā'uddīn Naqšband (m.1389) l'eponimo fondatore dell'ordine dei Naqšbandī, disse chiaramente che chi intende percorrere il cammino spirituale: «Se non considera la propria anima mille volte più vile dell'anima del Faraone, non potrà mai posare il suo piede sulla Via».21

Sempre 'Alā'uddīn 'Aț̣ār riferisce ciò che disse una volta Huwāja Bahā’uddīn:

«In questa Via il lavoro principale è negare se stessi, essere nulla, umiliarsi (nafì-yi wuğūd va nistì va kam dīdan). È questo il bandolo della matassa che concede la fortuna di giungere fino alla Potenza. Così durante la via mi sono confrontato con ogni categoria dell'essere, mi sono misurato con ogni atomo e particella delle creature, e ho visto che in realtà tutto era migliore di me. Sono arrivato anche a valutare il grado

18 Corano XX:14.

19 'Aț̣ār, Farīduddīn: Tadkirat al-Awliy ă’, testo persiano a cura di Mohammad Estelami, Teheran 1346 h. š., p. 140.

20 Hamid Algar : "Eléments de provenance malâmâtî dans la tradition primitive naqshbandî", cit., p. 34.

21 Salāḥ ibn Mubārak Buhārī: An̄̄s al-tālibìn, cit., p.31. 
delle virtù delle creature e ho trovato in loro dei pregi, mentre in me stesso non ne ho riscontrato alcuno. Sono arrivato a misurare le qualità di un cane, immaginando che non ne avesse alcuna - una volta ne ero fermamente convinto - ma alla fine ho visto che anche quello aveva dei pregi, e ho assodato che in me di pregi non ce n'erano di alcun genere.

\author{
Meglio di chiunque altro sono informato su me stesso, \\ certo migliore di un cane non sono, anzi peggiore! \\ Ogni volta guardo alla mia condizione: \\ essa non vale un granello, dalla testa ai piedi! ${ }^{22}$
}

\title{
LA LUGE E L'OMBRA
}

Nel 1599 Šayh Aḥmad Sirhindī fu iniziato all'ordine naqšbandī e sotto la direzione di Huwāja Bāqī bi-Llāh sperimentò un progresso assai veloce sul sentiero spirituale, tanto che dopo soli cinque mesi il maestro gli conferì l'autorizzazione (iğăza) a iniziare e istruire discepoli. Il suo incontro con Huwāja Bāqī bi-Llāh fu un punto cruciale nella sua vita ed ebbe un così forte effetto su di lui, che finì per considerare tutte le sue precedenti esperienze irrilevanti.

Nelle lettere che Aḥmad Sirhindī inviò a Huwāja Bāqī bi-Llāh, traspare l'intenzione di ottenere la supervisione su tutti i suoi progressi spirituali. In una lettera, in particolar modo, egli si rivolge a Ḩwāja Bāqī bi-Llāh informandolo di alcuni fatti particolari; gli narra, infatti, di come percorrendo il cammino, attraversando una delle prime stazioni, Iddio gli aveva messo sul sentiero la visione dei propri difetti e delle proprie debolezze e il biasimo per la mancanza di sincerità d'intenzione:

«Non mi era possibile compiere nessuna buona azione senza che io diffidassi di tale buona azione; anzi, finché in un modo o nell'altro non mi biasimavo per essa, diventavo inquieto e impaziente. Da parte mia so bene che nessuna delle mie azioni merita di essere registrata dall'angelo della destra, e so anche che i fogli del libro della destra [dove sono scritte le buone azioni] sono vuoti e lo scriba è ozioso e disoccupato. Come posso meritare la Sua Presenza, Sublime ed Eccelso, se tutti quelli che sono al mondo, anche un infedele europeo ( $k \bar{a}$ frr-i farang), un ateo o un eretico, sono migliori di me ed io sono peggiore di tutti loro?». ${ }^{23}$

22 Ivi, p.29.

23 Šayh Aḥmad Sirhindī: Maktūbāt-i Imām-i Rabbān̄̄, Karachi-Istanbul 1977, libro I, letteral 1, vol. 1, p.24. 
Una sentenza inserita nella biografia di Mīrzā Maẓhar Jān-i Jānān (m. 1781), uno dei discendenti spirituali di Šayh Aḥmad Sirhindī, riprende lo stesso tema e introduce un argomento peculiare della metafisica sirhindiana: «Finché il sufi non vede se stesso peggiore di un miscredente occidentale (kâfir-ifarang), è peggiore di un miscredente occidentale». ${ }^{24}$

Un discepolo di Mīrzā Mazhar Jān chiese stupito al maestro una spiegazione sul senso di questa frase, poiché a rigor di logica le virtù di un credente, se è per giunta un șūfì, non potevano essere peggiori dei vizi di un miscredente europeo. Nella sua risposta Mazhar Jān disse che la frase in fondo non conteneva un giudizio sulle virtù del musulmano o sui vizi dell'europeo, ma riguardava invece la convinzione, scontata anche nel credente più devoto, che pregi, virtù, buone qualità e quant'altro, siano meriti del credente e che gli appartengano di diritto come il frutto di un'acquisizione personale. La differenza tra ciò che l'essere umano immagina di sé stesso è ciò che egli è in realtà, sta nel fatto che tutte le qualità positive e le virtù lodevoli che egli attribuisce a sé stesso, non sono altro che un riflesso delle ombre delle Qualità divine che s’imprimono sul suo essere temporaneo, o meglio sul suo essenziale nonessere, ottenendole in prestito dal Principio.

Così prosegue Maẓhar Jān nella sua risposta:

«Non è un segreto che nel mondo sensibile, se qualcuno guarda in uno specchio che riflette le luci del sole, la prima cosa che vede sono proprio le luci, non lo specchio, perché lo specchio è celato e nascosto dal loro fulgore; ma se per caso questo qualcuno guardasse lo specchio in sé, per prima cosa vedrebbe proprio il piano riflettente e non le luci riflesse, perché lo sguardo non si fisserà su ciò che in esso appare. Dunque, quando lo sguardo del sufi si posa sull'immagine di cose nobili e meno nobili, vede da un lato quei luoghi epifanici (mažăhir) in cui si è manifestato l'Essere supremo, che è l'origine del bene; ma non appena egli guarda in sé stesso, il suo sguardo cadrà sul lato del non-essere, che è la sua propria essenza e l'origine del male, e vedrà se stesso del tutto privo di bene e di perfezione. Così, non trovando in sé il bene e la perfezione presi a prestito e acquisiti dal lato dell'essere, necessariamente comprenderà di essere peggiore di un miscredente occidentale e di altre cose miserabili». ${ }^{25}$

Tutto ciò è espresso da Šayh Aḥmad Sirhindī in una delle sue lettere:

«Secondo la conoscenza dell'umile scrivente, le realtà degli esseri contingenti (haq $\bar{a}$ 'iq-i mumkināt), come già è stato spiegato in altre lettere, sono costituite da dei non-esseri

24 Šăh Ġulām 'Alī: Maqāmāt-i Maz̧hariyya, Istanbul 1993, pp. 131-132. Demetrio Giordani: La vita perfetta di Mîrzâ Mazhar Jân-i Jânân (1699-1781), Mimesis, Milano 2010, pp. 141-143.

25 Šāh Ġulām 'Alī: Maqāmāt-i Maz̧hariyya, cit., p.132 
('adamāt), l'origine d'ogni male e imperfezione, sui quali sono andate a riflettersi le forme ideali (suwar-i ílmiyya) dei Nomi e degli Attributi divini, che vengono così a manifestarsi in questi non-esseri. Il succo del discorso è che i non-esseri equivalgono alla materia universale (hayūla ), mentre i riflessi ('ukūs) che si riverberano su di loro equivalgono alle forme che dimorano in quella materia. I non-esseri si particolarizzano (tašahhus) e si differenziano (tamayyuz) grazie alla manifestazione di quei riflessi, e di converso questi riflessi sussistono (qiy) $\bar{a})$ in quei non-esseri così differenziati». ${ }^{26}$

Seguendo il linguaggio della metafisica di Šayḩ Aḥmad Sirhindī, le realtà degli esseri creati e

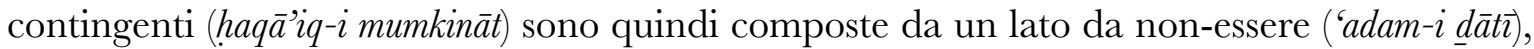
che è la vera fonte di ogni imperfezione e di ogni male, e dall'altro dalle ombre o dai riflessi degli Attributi divini essenziali (žilāl-i șifāt-i ḥaqūqiya) che sono l'origine di ogni bene e di ogni bellezza. Le realtà degli esseri contingenti, in quanto non esseri, sono poste di fronte ai Nomi e agli Attributi come specchi: esse riflettono le ombre e i riflessi dei Nomi e degli Attributi, e per aver accolto quelle ombre e quei riflessi acquistano così un certo grado di stabilità (tubüt).

«Quando il Vero - sia glorificato ed esaltato! - vuole manifestare le perfezioni della Sua Essenza, dei Suoi Attributi e dei Suoi Nomi e desidera rivelarsi nei gradi del nonessere, in oggetti assunti come luoghi epifanici e come specchi, Egli assegna a ciascuna delle perfezioni [che vuole manifestare] un non-essere distinto dagli altri non-esseri ( $\left.a^{6} d \bar{a} m\right)$ che le funga da specchio. Il riflesso nello specchio è, di fatto, l'immagine rovesciata di una cosa e al tempo stesso il mezzo che lo fa manifestare; si dice, infatti, che: "Le cose si palesano per i loro contrari" (wa-bi-diddihà tatabayyana al-ašy $\bar{a}$ )». ${ }^{27}$

In questo modo le realtà degli esseri contingenti, che sono accidenti instabili e temporanei, diventano delle realtà relativamente stabili, per la combinazione di non-essere e d'essere. In questo modo tali realtà manifestano le caratteristiche del bene e del male: dal lato della loro non-esistenza essenziale traggono il male, e dal lato dell'essere ombra e riflesso del divino, il bene.

Dal punto di vista della realizzazione iniziatica, l'esperienza dell"“estinzione in Dio" ( $f a n \bar{a})$ acquista un significato del tutto particolare: poiché sulla via verso Dio si giunge alla fine a sperimentare che è Dio l'unico detentore dell'Essere, mentre l'uomo ne è solo un depositario temporaneo, l'esperienza del fan $\bar{a}$ ' pone il șüfì nella condizione di sperimentare la consapevolezza della propria nullità essenziale. Se fino allora si era erroneamente attribuito un'identità e una presenza illusorie, una volta svanita l'illusione, cesserà di attribuire a se stesso un'individualità autonoma e tornerà a restituire la parola "io" al suo legittimo proprietario.

26 Sirhindī: Maktūbāt, libro II, lettera n. 94, vol. 2, p. 237.

27 Sirhindī: Maktūbāt, libro III, lettera n.60, vol. 2, p.405. Assioma citato anche in III, 61 e III, 76. 
Šayh Aḥmad Sirhindī ha chiarito questo suo punto di vista in molti dei suoi scritti, in particolare in una lettera indirizzata al suo terzogenito, che diverrà poi suo successore nella linea iniziatica dell'ordine naqšbandī.

\section{LETTERA N 62 VOLUME III}

Al figlio Hwwāja Muhammad Ma'șum. Sull'impossibilità dell'uomo di estinguersi, poiché l'uomo è essenzialmente non-essere ('adam-i $\underline{d} \bar{a} t \bar{\imath})$.

«La realtà (haquiqat) e l'essenza ( $\underline{d} \bar{a} t)$ dell'uomo sono la sua stessa anima razionale (nafs-i nātiqa) cui ogni singolo individuo allude con il termine "io", ma la cui realtà di fondo è il non-essere ('adam). Tuttavia, poiché su questo non-essere vanno a riflettersi l'Essere e le sue qualità, l'anima pensa di esistere, di essere viva, di essere conoscente e potente in modo autonomo, e presume che attributi perfetti come la vita, la scienza, ecc. derivino da sé stessa e che lei sia il motivo della loro esistenza.

A causa di questa illusione, essa ha la certezza di essere perfetta e buona, e dimentica la malvagità e l'imperfezione che le sono proprie, che le derivano dal non-essere, che non è altro che male puro (šarr-i maḥ) $)$.

Ma allorché la sollecitudine divina - che sia magnificata la Sua sovranità! - si volge verso di lei e la libera dall'ignoranza composita e dal credere nell'errore, essa si rende conto che queste perfezioni provengono da un altro luogo, che queste qualità perfette non provengono da lei, né che esse esistono per causa sua, e si accorge che la sua realtà e la sua essenza sono il nonessere, che è male puro e mera imperfezione.

Se questa visione prevale nell'anima per via della generosità divina, le perfezioni vengono giustamente rese al loro Padrone ed essa restituisce per intero questo deposito a chi glielo aveva affidato, e saprà di non consistere altro che in puro non-essere e di non aver mai fiutato in sé neppure l'odore del Bene. Allora di lei non rimane né nome, né impronta, né essenza, né traccia.

Il non-essere infatti è un puro nulla ( $l \bar{a}$ šay), non possiede alcuna permanenza in nessun grado; se per ipotesi gli fosse attribuito un qualsiasi grado di permanenza, non gli si potrebbe negare ogni genere di perfezione: la permanenza è infatti la perfezione stessa, anzi la madre di tutte le perfezioni. 
Da tutto ciò risulta necessariamente che raggiungere questa estinzione,28 che è la più totale $\mathrm{e}$ perfetta, non comporta affatto una cessazione dell'essere di colui che si estingue, poiché questi non ha mai posseduto un essere di cui si possa concepire la cessazione; era solo un non-essere che si era attribuito un'esistenza illusoria. Così, quando viene a cessare quest'illusione, e termina la percezione illusoria, ciò che rimane altro non è che puro non-essere, cioè un nulla evanescente. Quindi, ciò che è indispensabile è la cessazione della percezione (zawāl-i šuhūd $\vec{\imath})$,

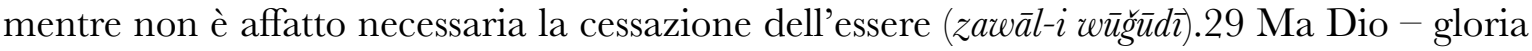
a Lui! - meglio conosce le cose come sono in realtà». ${ }^{30}$

\section{GONGLUSIONI}

Le descrizioni che i primi autori del tasawreuf danno del gruppo dei Malāmatiyya, la "Gente del Biasimo", sono narrazioni sommarie, spesso corredate con brevi cenni biografici dei personaggi più noti. Secondo quello che ci perviene da 'Alī ibn 'Uțmān al-Hujwīrī, bisogna considerare la "Via del Biasimo" come un'attitudine spirituale sporadica e non come una vera e propria tarīqa. Al-Sulamī identifica i primi Malāmatiyya nel gruppo che originariamente si riuniva a Nišāpūr, intorno ad alcune figure carismatiche che egli conosceva bene, per via della testimonianza di suo nonno, che era stato uno dei membri di quel gruppo. Egli è l'autore di un primo trattato sistematico sulle dottrine e il metodo del gruppo di Nīšāpūr, la Risāla al-malāmatiyya, secondo cui il centro della pratica dei Malāmatiyya era la dissimulazione del loro vero stato, allo scopo di evitare l'adulazione dei profani e i pericoli di una fama indebita, considerata come il peggior veleno per l'anima. L'attenta osservazione dei moti dell'anima inferiore e dei suoi stratagemmi, la severa analisi di ogni stato interiore, il biasimo e il disprezzo per sé stessi, erano l'autentica pratica dei Malāmatiyya, che aveva come obiettivo finale la realizzazione della sincerità assoluta (ihlass) del culto. Un paio di secoli più tardi si sviluppò nella regione della Transoxiana una corrente sapienziale con caratteristiche

28 «Ovvero quella che deriva dalla suddetta visione che predomina». Glossa in margine al testo, p. 410. 29 In questo risiede una differenza peculiare tra la corrente della wahdat al-wuğùd e quella della wahdat al-šuhūd di cui Šayh Ahmad Sirhindī è il teorico principale. Tale differenza è riaffermata anche in altre

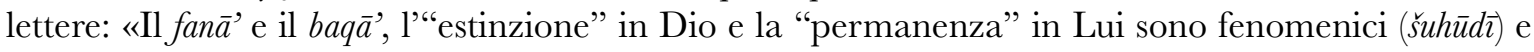

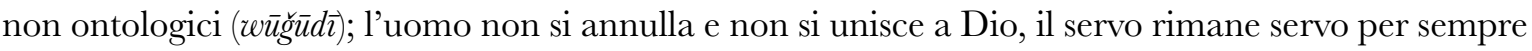
e il Signore rimane Signore in eterno. Quelli che affermano che il fan $\bar{a}$ ' e il $b a q \vec{a}$ ' riguardano l'essere, quasi che l'uomo infranga i suoi limiti esistenziali per riunirsi al suo Principio, che è invece libero da ogni limite e condizionamento, sono degli eretici. Costoro pensano che l'essere si annulli per permanere nel Signore, come una goccia d'acqua che si perde nel mare infrange i suoi limiti per unirsi all'Assoluto. Iddio ci protegga da queste cattive convinzioni». Sirhindī: Maktūbāt, libro II, lettera n.99, vol. 2, p. 257.

30 Sirhindī: Maktūbāt, libro III, lettera n.62, vol. 2, pp. 497-499. 
analoghe a quella dei Malāmatiyya di Nī̌sāpūr, questa corrente era denominata la "Via dei Maestri Antichi" (Hwāăgağann) e comprendeva vari gruppi impegnati in diversi tipi di pratiche rituali. I nomi di sette di questi Maestri sono iscritti nella silsila della Naqšbandiyya; due di loro furono i maestri di Ḩwāja Bahā'uddīn Naqšband. Le pratiche basilari di questa corrente erano la "menzione del Nome di Dio in segreto" (dikr-i hafî) e la "solitudine tra la folla" (halwat dar anjoman), prassi comune anche tra i primi Malāmatiyya. Alla fine del XVI secolo, Šayh Ahmad Sirhindī fu iniziato all'ordine naqšband̄̄ in India da Ȟwāja Bāqī bi-Llāh. Per l'elevatezza dei suoi stati spirituali e l'impatto che ebbero le sue dottrine nell'ambiente religioso dell'India del XVII secolo, e soprattutto per il rinnovamento che generarono le sue lettere all'interno degli ambienti del Sufismo, fu soprannominato il "Rinnovatore del Secondo Millennio dell'Islām" (muğaddid-i alf-i țān $\vec{\imath}$. Egli fu fedele alla tradizione dei Huwāğagāān e i suoi insegnamenti proseguono nel solco tracciato dalle opere di Ḩwāja Bahāùddīn Naqšband, con la fondamentale differenza che la sua dottrina ha reso esplicito ciò che i maestri delle generazioni precedenti avevano accennato appena, o rivelato sotto allusioni o metafore. Nell'opera di Sirhindī, "La Via del Biasimo" acquista una chiara solidità dottrinale, che deriva dall'individuazione della realtà essenziale dell'essere contingente come nulla assoluto ( $l \bar{a} \check{s} a y)$ e male puro (šarr-i maḥ), che rimane tale se su di esso non si rifrangono le Ombre dei Nomi e delle Perfezioni divine. Dal suo punto di vista, nulla appartiene all'uomo se non il suo essenziale non essere, l'illusione che virtù, pregi e buone qualità siano acquisiti per proprio merito dal credente, è ipocrisia, l'illusione di possedere un'identità autonoma dal Principio Assoluto, merita il biasimo. In questa visione riaffiorano l'umiltà e la modestia dei Malāmatī: l'evitare di essere lusingati per le pratiche devote, il nascondersi dietro un aspetto insignificante, "l'isolamento nella folla", l'implacabile disapprovazione dei trucchi dell'anima inferiore, rivela la consapevolezza della radicale nullità dell'essere contingente di fronte all'Assoluto.

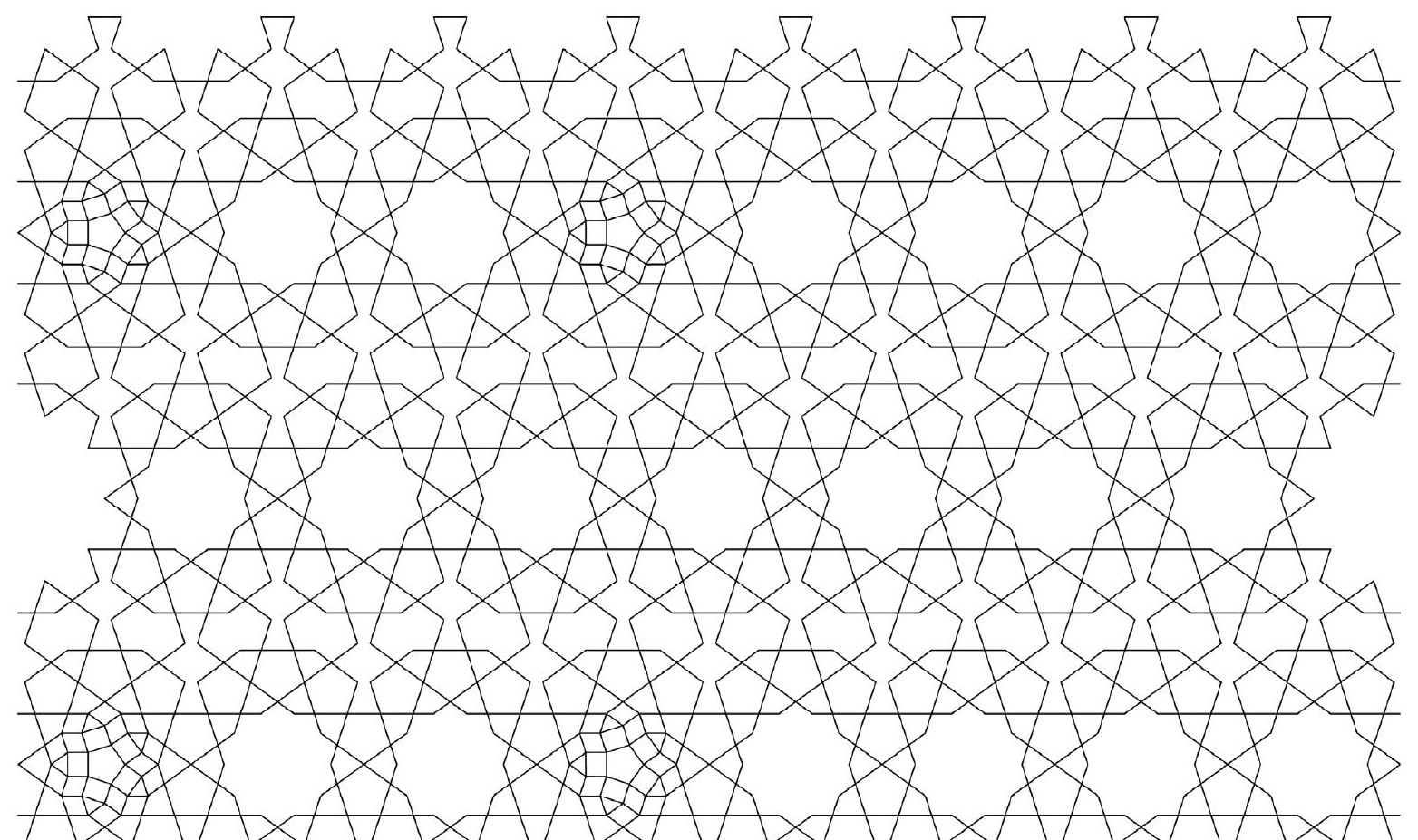




\section{BIBLIOGRAFIA}

Al-Iṣfahānī Abū Nu'aym Aḥmad ibn 'abd Allāh: Hilyat al-Awliyā' wa tabaqāt al-asfyya', 10 voll., Dār al-kutub al-'ilmiyya, Bayrūt 1988.

Al-Qušayrī Abū l-Qāsim: Al-Risālah al-Qušayriyya, Dār al-Kutub al 'Ilmiyyah, Bayrūt, 2001. Trad. ingl. Alexander D. Knysh, Al-Qushayri's Epistle on Sufism, Garnet, Reading, 2007.

Alam Irshad: Faith Practice Piety. An Excerpt from the Maktubat-i Imami-i Rabbani. Dhaka 2010.

Algar Hamid : "A brief History of the Naqshbandī Order", in Marc Gaborieau, Alexandre Popovic e Thierry Zarcone (a cura di): Naqshbandis. Cheminements et situation actuelle d'un ordre mystique musulman. Actes de la Table Ronde de Sèvres, 2-4 mai 1985. Istanbul 1990.

Id.: "Eléments de provenance malâmâtî dans la tradition primitive naqshbandî" in: MelamisBayramis, Études sur trois mouvements mystiques musulmans. Réunies par Nathalie Clayer, Alexandre Popovic et Thierry Zarcone. Les Éditions ISIS Istanbul 1998.

Al-Ǧurǧān̄ī 'Alī ibn Muhammad al-Šarīf: Kitāb al-Tárîfăt. Librairie du Liban, ed. G.Flugel, Bayrūt 1985.

Al-Huğwīrī 'Alī ibn 'Uțmān: Kašf ol-Mahğğub, ed. Mahmūd Abedī, Teheran 1383 (h.šs.).

Id: The Kashf al-Mahjub the Oldest Persian Treatise on Sufism, a cura di R.A. Nicholson, Lahore 1976.

Al-Kāšifi 'Alī ibn Ḥusayn al-Wā'iz Șafì: Rašahăt'ayn al-Hayāt, Taškent 1911.

Id.: Rashahât 'ayn al-hayât. Beads of Dew from the Source of Life, traduzione inglese a cura di Mukhtar Holland, Lauderdale 2001.

Al-Sahlajī Muhammad ibn 'Alī: Il libro della Luce (Kitāb al-Nūr). Fatti e detti di Abū Yazīd AlBistāmmi. Introduzione, traduzione e note a cura di Nahid Norozi, Ester, Torino 2018.

Al-Sulamī Abū 'Abd al-Raḥmān: "Bayān aḥwāl al-ṣūfiyya" in: Tis'a kutub fi usūl al-tasawreñf wa’l zuhd li Ab̄̄ Ábd al-Rahmānn al-Sulamī. Ed. Suleyman Ibrahim Atiş, Riyāọ, 1993.

Id: Al-Ṭabaqāt al-Süfyyya, Al-Qāhira 1997.

Id: Risāla al-malāmatiyya, trad. it.: I custodi del segreto, a cura di G. Sassi, Milano 1997, pp. 38-39.

Id.: La scala di Luce. Tre antichi testi di scuola malāmatī. Traduzione dall'arabo a cura di Demetrio Giordani. Il Leone verde, Torino 2006.

Id: Risāla al-Malāmatìyya, in Abū al-'Alā al-'Afifì: Al-Malāmatìyya wa al-Süfyyya wa ahl alFutuwrwa, Beirut-Baghdad 2015.

Alvi Sajida S.: "The Naqshbandī Mujaddidī Sufi Order's Ascendancy in Central Asia Through the Eyes of its Masters and Disciples (1010S-1200S/1600S-1800S)" in: Reason and 
Inspiration in Islam. Theology, Philosophy, and Mysticism in Muslim Thought. Essays in Honour of Hermann Landolt. Edited by Todd Lawson, London New York 2005.

Ansari Abdul Haqq Muhammad: Sufism and Sharîa. A Study of Shaykh Ahmad Sirhindî’s Effort to Reform Sufism. Leicester 1986.

'Ațtār Farīduddīn: Tadkirat al-Awliy $\bar{a}$ ', testo persiano a cura di Mohammad Estelami, Teheran 1346 h. š.

Buehler Arthur: "The Naqshbandiyya in Tīmūrid India: the Central Asian Legacy", in Journal of Islamic Studies 7-2, 1996.

Id.: Fìhāris-i taḥ̂̄l̄̄-yi Maktūbāt-i Aḥmad Sirhind̄̄, Lahore 2001.

Id.: Revealed Grace: The Juristic Sufism of Ahmad Sirhindi (1564-1624), Fons Vitae, Louisville, 2011.

Buhārī Salāḥ ibn Mubārak: An̄̄s al-țālibīn wa 'uddat al-șālihiñn. Kanpūr 1901, Istanbul 2010.

Chittick William C. : The Sufi Path of Knowledge. Ibn al-Arabi's Methaphysics of Immagination, SUNY 1989.

Chodkiewicz Michel: "Quelques aspects des techniques spirituelles dans la Tarîqa Naqshbandiyya" in Marc Gaborieau, Alexandre Popovic e Thierry Zarcone (a cura di): Naqshbandis. Cheminements et situation actuelle d'un ordre mystique musulman. Actes de la Table Ronde de Sères, 2-4 mai 1985, Istanbul 1990.

Id.:"Les Malâmiyya dans la doctrine de Ibn 'Arabî" in Melâmis-Bayrâmis. Études sur trois mouvements mystiques musulmans. Réunies par Nathalie Clayer, Alexandre Popovic et Thierry Zarcone. Les Éditions ISIS Istanbul 1998.

Friedmann Yonahan: Shaykh Ahmad Sirhindi: An Outline of his Thought and a Study of His Image in the Eyes of Posterity. McGill- Queen's University Press 1971.

Giordani Demetrio: La vita perfetta di Mîrzâ Mazhar Jân-i fânân (1699-1781), Mimesis, Milano 2010.

Id: I Naqshbandī: uomini, storia e dottrine di un ordine sūfī, Milano, Jouvence 2019.

Ġulām ‘Alī Šāh: Maqāmāt-i Mažhariyya, Istanbul 1993.

Ibn 'Arabī Muḥyīddīn: Al-Futūhāt al-Makkiyya, Il Cairo 1329 h. (4 vol.).

Id: Il mistero dei custodi del mondo (Kitâb manzil al-qutb wa maqâmu-hu wa hâlu-hu) traduzione a cura di C. Casseler, Torino 2001.

Molé Marijan: "Autour de Daré Mansour: l'apprentissage mystique de Bahāuddīn Naqšband", Revue des Etudes Islamiques, 1959. 
Nīšābūrī Mīr 'Abd al-Awwāl: "Malfūẓāt-i Ahrār", in: Aḥwāl va Suhanān-i Hwwāja 'Ubaydullāh Ahrār, a cura di 'Ārif Nawšāhī, Teheran 1380 h. š.

Paul Jürgen: "Forming a Faction: the Himāyat System of Khwaja Ahrar", in fournal of Middle East Studies, vol. 23, N4 4 (Nov.1991).

Id.: Organization and doctrine: The Khwäjagān/Naqshbandīya in the first generation after Bahä'uddīn. Berlin: Das Arab Buch 1998.

Id.: "Solitude within Society: Early Khwājagān̄̄ Attitudes toward Spiritual and Social life" in Paul L. Heck (editor) Sufism and Politics, Princeton University 2007.

Sirhindī Šayh̆ Aḥmad: Maktūbāt-i Imām-i Rabbān̄̄, 2 Voll., Karachi-Istanbul 1977.

Sviri Sara: "Al-Hakîm alTirmidhî and the Malâmatî Movement" in: The Heritage of Sufism, vol. I, Classical Persian Sufism from its Origins to Rûmî (700-1300), a cura di Leonard Lewisohn, Oxford 1999.

Ter Haar Johann G.J.: "The Naqshbandi Tradition in the Eyes of Ahmad Sirhindī," in Naqshbandis. Cheminements et situation actuelle d'un ordre mystique musulman. Actes de la Table Ronde de Sèrres, 2-4 mai 1985. Istanbul 1990

Id.: Follower and Heir of the Prophet. Shaykh Ahmad Sirhindî (1564-1624) as Mystic, Leiden, Brill, 1992. Ventura Alberto: Profezia e santità secondo Shaykh Ahmad Sirhindi, Cagliari 1990.

Weismann Itzchak: The Naqshbandiyya. Orthodoxy and activism in a worldwide Sufi tradition, London and New York 2007.

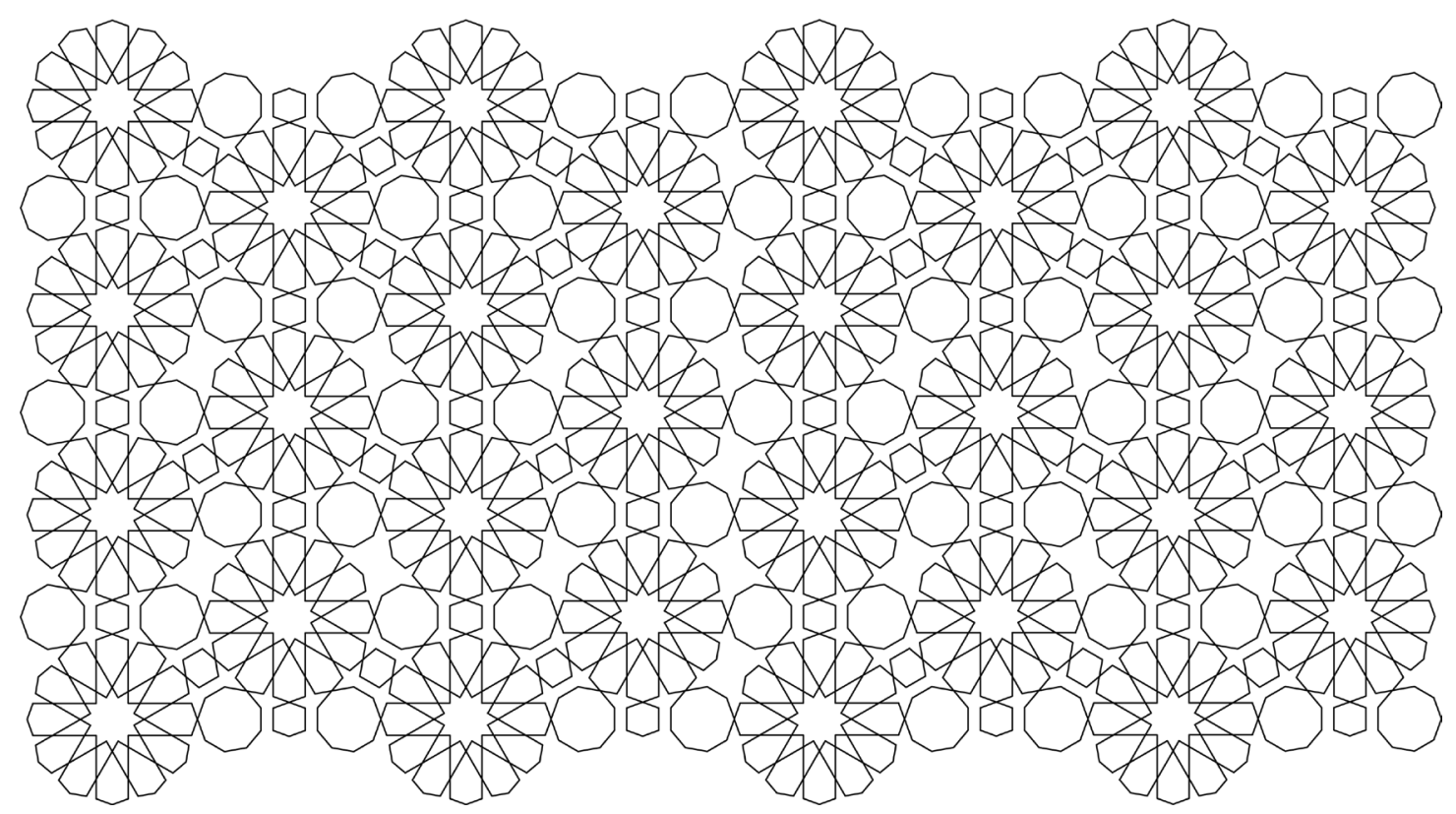

